\title{
Democracia racial brasileira 1900-1990: um contraponto americano
}

\author{
GEORGE REID ANDREWS
}

$\mathrm{O}$

BRASIL É UMA DAS MAIORES sociedades multirraciais do mundo e lar do maior componente isolado da diáspora africana além-mar (1). Durante a primeira metade dos anos 1900, foi freqüentemente descrito, tanto por observadores nativos quanto estrangeiros, como uma democracia racial na qual negros, mulatos e brancos viviam sob condições de igualdade jurídica e, em grande medida, social. Durante a segunda metade do século, entretanto, essa descrição foi inteiramente revisada. A partir de 1940 até o presente, os censos nacionais vêm documentando disparidades persistentes entre as populações branca e nãobranca em educação, realização vocacional, ganhos e expectativa de vida. Levantamentos realizados em pesquisas têm demonstrado que as atitudes e os estereótipos racistas referentes a negros e mulatos estão amplamente disseminados por toda a sociedade brasileira. E os afro-brasileiros relatam ser vítimas de racismo e discriminação sutis e, por vezes, não tão sutis assim. Portanto, embora os observadores que escreveram nas décadas de 30 e 40 tenham se concentrado na qualidade harmoniosa e igualitária da interação racial no Brasil, discussões semelhantes nos anos 80 e 90 enfatizaram "a percepção, ainda mais disseminada, de que [o conceito de] democracia racial, em suas versões oficial e extra-oficial, não reflete a realidade brasileira...". "O mito da democracia racial parece estar definitivamente em seu túmulo", observou a revista Isto é durante as comemorações que marcaram o centenário da abolição da escravatura, em 1988: "discriminação racial", e não democracia racial, "é a base da cultura brasileira", argumentou o historiador Décio Freitas (2).

O que explica essa transformação nas caracterizações das relações raciais brasileiras? Defendi, alhures, que os desacordos e debates em torno do conceito da democracia racial no Brasil estão intimamente vinculados às tensões que cercam a teoria e prática da democracia política no país. Originalmente, a democracia racial foi concebida como parte de uma campanha ideológica maior para justificar o domínio autoritarista e oligárquico no Brasil. Quando tal modelo de governo passou a sofrer crescentes ataques após 1945, o mesmo aconteceu com a noção de o Brasil ser uma democracia racial. E embora a luta contra o autoritarismo tenha atingido seu clímax na década de 80 , durante os últimos anos da ditadura militar (1964-85), o mesmo aconteceu com a imagem do Brasil como uma "África do Sul sem apartheid" - isto é, uma sociedade sem a segregação racial imposta pelo Estado e, não obstante, afligida por extrema desigualdade racial (3). 
Essa explanação do declínio da democracia racial concentrava-se nos fatores internos específicos do Brasil. Neste ensaio, gostaria de desviar a atenção para o impacto dos fatores externos sobre a política racial e sobre o pensamento racial brasileiros. Fluxos de idéias, imagens, práticas e instituições transnacionais constituem parte indissociável da causalidade histórica em todas as sociedades modernas. Foram particularmente importantes nas sociedades periféricas do Terceiro Mundo que, devido à sua dependência histórica, dedicam grande atenção às tendências e aos eventos nos países centrais e são fortemente afetadas por eles. Essa dependência não significa, contudo, que as sociedades periféricas sejam receptoras passivas das forças e influências intelectuais e políticas (e, nesse sentido, econômicas) que emanam do centro. Pelo contrário, engajam-se em um complexo diálogo com atores metropolitanos, filtrando, avaliando e re-elaborando idéias e asserções importadas de fora e transformando-as em novos organismos (freqüentemente, bem originais) de pensamento e preceitos para a ação. Muitas vezes, este é um diálogo essencialmente unilateral, no qual as sociedades centrais falam, mas não ouvem. No caso das relações raciais brasileiras, contudo, eruditos e intelectuais dos países centrais de fato ouviram e dedicaram atenção àquilo que estava acontecendo no Brasil.

Foi este especialmente o caso nos Estados Unidos. Ao mesmo tempo em que enfrentavam seus próprios dilemas raciais, nada puderam fazer senão perceber o caminho muito diferente tomado por sociedades latino-americanas em geral, e pela maior república da América do Sul em particular. Os brasileiros também perceberam a diferença e, da mesma forma que com o desempenho econômico e político, mediram o progresso social de sua nação em relação àquele de seu vizinho do Norte. O resultado foi uma extensa conversação, durante todo o século, entre os dois países - um contraponto americano, abrangendo tanto a América do Norte como a do Sul - sobre o tópico da raça. Dadas as disparidades de poder e influência existentes entre elas, até agora os impactos dessa conversação têm sido maior no Brasil que nos Estados Unidos. Mas suas reverberações poderão ser mais fortemente sentidas nos anos vindouros, já que o próprio sistema de relações raciais dos Estados Unidos parece estar se aproximando cada vez mais daquele do Brasil (4).

\section{Democracia racial, 1900-1950}

A conversação iniciou-se no final do século XIX com a chegada ao Brasil, oriundas do Atlântico Norte, das doutrinas de racismo científico, darwinismo social e, em sua forma mais extremada, supremacia racial dos brancos. A resposta das elites e dos intelectuais brasileiros a tais idéias foi ambivalente. Por um lado, as teorias raciais chegaram ao Brasil imbuídas do grande prestígio da ciência européia; e também harmonizavam-se com as noções nativas brasileiras da superioridade racial dos brancos. Por outro, a vigorosa condenação da mistura racial por parte do racismo científico constituiu devastadora crítica da sociedade brasileira - que, a partir de 1890, era constituída por um terço de mulatos e majoritariamente não-brancos - e previsão melancólica de seu futuro.

Alguns pensadores brasileiros - mais notavelmente o etnógrafo e médico 
Raimundo Nina Rodrigues - aceitaram os ditames do racismo científico, inclusive suas asserções sobre a "degenerescência mulata" (a despeito do fato de ser o próprio Rodrigues uma pessoa de raça mista). Outros, contudo, buscaram escapar das implicações abomináveis da teoria racista, alargando, de fato, seu poder explanatório na forma da tese do branqueamento. Os racistas científicos ortodoxos afirmavam a superioridade da herança racial branca, mas também defendiam que a herança era enfraquecida e minada pela mistura com raças inferiores. Os revisionistas da tese do branqueamento, como João Batista de Lacerda, diretor do Museu Nacional do Brasil, respondia que os racistas científicos também tinham pouca fé no poder dos genes brancos (ou, na linguagem da época, sangue branco). Nos casos de mistura racial, sustentavam eles, o componente genético branco tenderia a dominar; e se tal mistura fosse repetida durante várias gerações, o resultado final seria uma população branqueada na qual a ancestralidade africana e índia seria superada e neutralizada (5).

A tese do branqueamento salvou o Brasil da melancólica perspectiva de degeneração racial e manteve a esperança de, um dia, poder fazer parte da comunidade de nações brancas. Também constituiu poderoso incentivo para que os políticos brasileiros acelerassem o processo do branqueamento, pela exclusão dos não-brancos do pool genético do Brasil e pela ampliação do componente europeu. A Constituição de 1891 proibiu a imigração africana e asiática para o país e os governos federal e estaduais da Primeira República (1891-1930) empreenderam esforços orquestrados no sentido de atrair a imigração européia ao país. Tais esforços deram frutos na forma de 2,5 milhões de europeus que migraram para o Brasil entre 1890 e 1914, 987 mil com sua passagem de navio paga por subsídios do Estado. Após um período menos significativo quanto à imigração, à época da Primeira Guerra Mundial outros 847 mil europeus chegaram ao país (6).

Graças aos imigrantes, o censo nacional de 1920 confirmou "uma tendência que está se tornando mais visível e definida: a tendência no sentido da progressiva arianização de nossos grupos regionais. Ou seja, o coeficiente da raça branca está se tornando cada vez maior em nossa população". A experiência do Brasil com o branqueamento estava refutando, de forma conclusiva, os racistas científicos, um dos quais (o antropólogo francês Vacher de Lapouge) havia observado em 1890, segundo o censo, que "cem anos a partir de agora, o Brasil sem dúvida constituirá um imenso estado negro, a não ser que, como é provável, reverta ao barbarismo". Examinando tais previsões do ponto de vista de 1920, "temos o direito, sem dúvida e sem a menor sombra de irreverência, de sorrir" (7).

Pode-se supor que o sorriso tenha sido um tanto forçado. A confiança das asserções do censo foi falseada pelo fato de que o documento não continha dado algum que fosse sobre a composição racial da população, e não houve qualquer censo nacional que o tivesse feito desde 1890. Não obstante, era evidente que o branqueamento estava impactando a sociedade brasileira, introduzindo tensões e conflitos não antevistos. Os trabalhadores nativos enfrentavam intensa competição por parte dos imigrantes e contestavam energicamente a ostensiva preferência pelos europeus manifestada por vários empregadores. Os membros da classe mé- 
dia brasileira, particularmente os negociantes qualificados e pequenos comerciantes varejistas, enfrentaram competição semelhante por parte dos imigrantes e seus filhos. E mesmo os empregadores e as elites irritavam-se com os imigrantes, pois estes importavam para o Brasil as doutrinas estrangeiras de anarquismo e socialismo e um estilo novo e mais militante de organização trabalhista (8).

Por volta dos anos 20 e 30 o desencanto nacional com a imigração e europeização era abundantemente evidente. A xenofobia de direita tornou-se um elemento central da mobilização política da classe média, culminando no movimento Integralista de cunho fascista, fundado em $1932 \mathrm{em}$ São Paulo, o estado mais afetado pela imigração européia (9). São Paulo já havia abolido seu programa de subsídios para a imigração européia em 1927; e em 1930 e 1931, o governo federal impôs restrições à imigração ao país, bem como sobre o emprego de indivíduos de nacionalidades estrangeiras no comércio e na indústria (10).

O esforço de transformar o Brasil numa sociedade branca européia nos trópicos fracassou. Ao fazê-lo, reabriu a questão do caminho do desenvolvimento futuro do Brasil e do caráter racial de sua identidade nacional. Em 1933, uma resposta foi oferecida pelo intelectual e teórico social Gilberto Freyre, que retomou o diálogo entre o Brasil e seus interlocutores do Atlântico Norte, mas agora em termos diferentes. Os proponentes do branqueamento tinham buscado europeizar o Brasil e torná-lo branco; Freyre, em contraste, aceitou que o Brasil não era nem branco nem europeu, e que nunca o seria. Em vez de a Europa dos trópicos, o Brasil estaria destinado a ser um novo mundo nos trópicos: um experimento exclusivamente americano no qual europeus, índios e africanos tinham se juntado para criar uma sociedade genuinamente multirracial e multicultural (11).

Freyre fora um estudante nos Estados Unidos nos anos 1910 e início da década de 20 e se horrorizara com as instituições e práticas Jim Crow (inclusive um linchamento) que testemunhou enquanto estudava na Universidade Baylor, no Texas, e fazia uma viagem pela região Sul (12). Sentindo aversão pela violência e brutalidade da segregação sulina, buscou refúgio numa visão do Brasil como uma democracia racial, "uma das uniões mais harmoniosas da cultura com a natureza e de uma cultura com a outra que as terras deste hemisfério já conheceu” (13). Essa união era simbolizada e corporificada pelos mulatos racialmente mistos, que Freyre considerava não como um estágio transicional na estrada que levava à brancura nacional, mas antes como o elemento mais caracteristicamente brasileiro da sociedade nacional. Ele rejeitou explicitamente as alegações dos racistas científicos de que "o mulato é incapaz de alcançar uma estabilidade como um igual social e intelectual do homem branco", argumentando que "no senso de corresponder mais intimamente ao meio brasileiro e de uma adaptação mais fácil e possivelmente mais profunda aos seus interesses, aos seus gostos, às suas necessidades, o mestiço, o mulato ou, para colocar de uma maneira mais delicada, a pessoa de cútis escura, pareceria exibir maior capacidade de liderança que o branco ou o quase branco". Como resultado dessa liderança, "o Brasil está se tornando mais e mais uma democracia racial, caracterizada por uma combinação quase singular de diversidade e unidade" (14). 
O choque do encontro de Freyre com a hostilidade e segregação racial dos Estados Unidos o levou a construir uma visão do passado do Brasil (e, por extensão, seu presente e futuro) que se mostrou profundamente atraente a muitos brasileiros. O racismo científico e sua variante brasileira, a tese do branqueamento, haviam considerado a história da escravidão e miscigenação do Brasil, e a população racialmente mista que era o seu legado, como obstáculos vergonhosos que tinham de ser superados se o Brasil quisesse entrar na comunidade das nações civilizadas. Freyre reabilitou esse passado, remodelando-o como a base de uma nova identidade nacional independente, pela primeira vez na história do Brasil, das normas e modelos europeus. De fato, já que os profundos males do racismo europeu foram completamente revelados durante os anos 30 e 40 , a democracia racial brasileira oferecia uma alternativa promissora e auspiciosa (15).

Os escritos de Freyre, portanto, tornaram-se a base de uma nova ideologia semi-oficial propagada em declarações públicas, escolas e universidades, e na mídia nacional. Contudo, tal ideologia teve uma recepção menos entusiástica por parte daqueles de quem se esperaria aplausos mais calorosos: os afro-brasileiros. Escritores e intelectuais negros vinham debatendo a democracia racial desde os anos 1880, quando o escritor mulato Lívio de Castro havia antecipado os argumentos de Freyre afirmando o "impulso democrático natural" e o "espírito democrático" da interação racial brasileira. As relações raciais no Brasil "se desenvolveram sem nenhuma luta entre as raças, evitando assim a criação de um sistema de castas como aqueles das antigas autocracias ... ou da confederação da América do Norte" (16). A citação de Castro aos Estados Unidos não foi acidental: da mesma forma que o próprio Freyre, os proponentes da democracia racial estavam fortemente motivados por sua aversão pelo sistema de relações raciais dos Estados Unidos, no qual se apoiavam fortemente para demonstrar a distinção e superioridade do sistema brasileiro. Em vários artigos, e num pequeno livro publicado durante os anos 20, o advogado e ativista trabalhista mulato Evaristo de Moraes citou os Estados Unidos como a "expressão máxima" do preconceito racial dos tempos modernos, e contrastou incisivamente sua segregação institucionalizada e linchamentos com a harmonia racial do Brasil, expressa na "fusão pacífica e produtiva das duas raças" (17). Parte considerável da imprensa afro-brasileira parecia concordar, publicando artigos regulares sobre a brutalidade e preconceito racial nos Estados Unidos. "Enquanto o negro norte-americano tira o seu blusão e se lança contra o branco numa luta sangrenta, tomado por um ódio mortal; ... o negro brasileiro estende sua mão fraterna aos seus irmãos brancos, fortalecendo os laços de amizade que os une ..." (18).

Outros escritores afro-brasileiros prontamente admitiram as transgressões dos Estados Unidos, mas advertiram que isso não significava necessariamente que o Brasil fosse racialmente igualitário. "Todos sabem”, observou o jornal Getulino em 1923, "que nos Estados Unidos o negro é considerado um leproso moral, e é tratado como o cão mais desprezível ... Mas afirmar a partir disso que não exista preconceito de cor no Brasil é como negar a derrota da Alemanha" (19). Um congênere de Getulino, O Clarim da Alvorada, inicialmente discordou: "nos Estados Unidos, onde o preconceito é um fato, o que pertence aos negros pertence 
aos negros, e o que pertence aos brancos pertence aos brancos. Mas não aqui; tudo que pertence ao Brasil, pertence a nós". Por volta de 1930, contudo, a posição de $O$ Clarim havia mudado e agora concordava, juntamente com significativa parte da imprensa negra, que "no Brasil, a igualdade racial é uma mentira" (20).

A imprensa afro-brasileira comentava não somente as deficiências óbvias da democracia racial: a discriminação que os não-brancos sofriam em sua busca de empregos, educação e outras oportunidade para progredir (21). Ela notava também uma das contradições internas menos óbvias da ideologia: embora afirmando a igualdade de todas as raças, a democracia racial expressava, simultaneamente, nítida preferência por mulatos racialmente mistos com relação a pessoas de ascendência inteiramente africana (22). Alguns escritores da imprensa negra aceitavam a superioridade racial dos mulatos com relação aos pretos (negros); mas a maioria rejeitava a noção de superioridade mulata e a sua divisão da população afro-brasileira em grupos antagônicos e rivais (23). Intelectuais e ativistas, como Vicente Ferreira (um preto) e José Correia Leite (um mulato), buscavam superar essa divisão favorecendo a utilização da palavra negro para agrupar as pessoas de ascendência africana mista e não-mista (24). Seus esforços, entretanto, tiveram pouco efeito e, em 1947, Correia Leite observou pesarosamente que "nesta nação de mestiços, são somente os negros que têm a coragem de denunciar o racismo". Como conseqüência, "continuamos a acreditar piamente na mentira sentimental de que, no Brasil, não existe preconceito. Mas o Brasil continua a ser um enorme alojamento de escravos, com alguns negros na Casa Grande” (25).

\section{O declínio da democracia racial, 1950-1990}

As críticas à democracia racial eram, portanto, desenvolvidas entre os intelectuais afro-brasileiros e na imprensa negra durante os anos 30 e 40 . Tais críticas, contudo, ocorreram bem fora dos limites da corrente principal dos discursos intelectual, acadêmico e oficial, nos quais o paradigma de Freyre mantinha uma hegemonia inquestionável (26). Foi somente depois que escritores e pesquisadores do establishment com a devida reputação começaram a questionar a democracia racial que sua defesa das concepções da identidade nacional começaram a se flexibilizar. E isso, por sua vez, só ocorreu depois que os eventos e influências internacionais começaram a exercer pressão sobre o Brasil, de fora de suas fronteiras.

O primeiro de tais eventos foi uma série de projetos de pesquisa sobre as relações raciais brasileiras, realizada por eruditos brasileiros, norte-americanos e franceses durante o início dos anos 50, sob os auspícios da recém-criada Organização Educacional, Científica e Cultural das Nações Unidas (Unesco). Em resposta aos recentes horrores do nazismo e do holocausto, a Unesco adotara, como parte de sua missão institucional, o combate ao racismo em todo o mundo. A democracia racial brasileira parecia oferecer uma alternativa particularmente promissora a tal racismo; num esforço de compreender como o igualitarismo racial havia ocorrido no Brasil e como funcionava na prática, a Divisão de Ciências Sociais da Unesco comissionou equipes de pesquisa nas duas principais cidades do Sudeste industrializado - Rio de Janeiro e São Paulo - e em várias pequenas cidades de Minas Gerais, e nos estados nordestinos da Bahia e de Pernambuco. Como 
freqüentemente acontece com uma pesquisa, os resultados não foram os esperados. Todas as equipes constataram elevados níveis de desigualdade entre as populações branca e não-branca, além de fortes evidências de atitudes e estereótipos racistas. Os pesquisadores do Nordeste tenderam a considerar que tais desigualdades expressavam mais as diferenças de classe que as diferenças raciais; ou seja, os negros sofriam discriminação e eram desprezados não por serem negros, mas por serem pobres (27). Os pesquisadores do Rio de Janeiro e de São Paulo, em contraste, deram mais ênfase ao preconceito e à discriminação baseados na raça, notando as diferenças no tratamento de acordo com os brancos e negros da classe trabalhadora e as enormes dificuldades enfrentadas por negros e mulatos cultos e qualificados que lutavam para se introduzir na classe média (28).

O segundo evento coincidiu com os projetos da Unesco. Em 1950 foi recusada a admissão da renomada dançarina afro-americana Katherine Dunham no Hotel Esplanada de São Paulo, onde ela tinha feito reservas durante excursão com sua Companhia no Brasil. Esse tratamento não era incomum para com afro-americanos - ou, neste sentido, afro-brasileiros - que viajavam pelo Brasil nos anos 30 e 40 (29). Mas o renome internacional de Dunham a colocou em categoria à parte, e suas vigorosas denúncias quanto ao incidente provocou comoção nacional e a aprovação pelo Congresso, no ano seguinte, do primeiro estatuto antidiscriminação do Brasil, a Lei Afonso Arinos (30).

Ambos os eventos - os projetos de pesquisa da Unesco e a Lei Afonso Arinos - marcaram o primeiro reconhecimento por autoridades acadêmicas e oficiais, respectivamente, de graves falhas na democracia racial do Brasil. Devido às brechas em seus dispositivos judiciais, os impactos da lei antidiscriminação foram bem modestos, tanto na época quanto a partir de então. Nos 34 anos entre sua implementação em 1954 e sua revisão pelos dispositivos antidiscriminação da Constituição de 1988, houve apenas três condenações sob a lei, com duas delas resultando em sentenças suspensas (31). Os projetos de pesquisa, contudo, deixaram um legado mais poderoso. Em primeiro lugar, o interesse da Unesco na problemática da raça no Brasil estimulou consideráveis discussão, reflexão e artigos por parte de ativistas e intelectuais afro-brasileiros do Rio de Janeiro e de São Paulo (32). Em segundo lugar, vários dos jovens estudiosos brasileiros que tinham participado de pesquisas - notavelmente Thales de Azevedo e Florestan Fernandes -, mais tarde prosseguiram e fizeram da desconstrução da democracia racial uma das questões centrais de suas carreiras acadêmicas. Continuaram a publicar críticas sobre as relações raciais brasileiras até os anos 60,70 e 80 , participando da formação de estudiosos mais jovens, que continuaram na mesma linha (33).

Mesmo em escala restrita, embora altamente estimulante, pesquisas e estudos desestabilizaram a unanimidade dentro da academia brasileira sobre a questão da democracia racial. Houve alguns sinais de tentativa de dissidência nos anos 40 entre os jovens pesquisadores em São Paulo (34); mas os livros e artigos das décadas de 50 e 60 marcaram a primeira ruptura da ortodoxia semi-oficial. Os governos militares dos anos 60 e 70 reagiram fortemente a essa ruptura, denunciando críticas à democracia racial como "atos de subversão" realizados por "esquerdistas 
... que buscam criar novas fontes de tensão e insatisfação para com o regime e suas autoridades devidamente constituídas" (35). Gilberto Freyre juntou-se ao ataque contra os "pseudo-sociólogos e comunistas" que, ao criticar a democracia racial, "agem de maneira antibrasileira" e assumem "uma atitude lamentavelmente antibrasileira" (36).

Apesar da oposição - e da tentativa de repressão - do governo, foi impossível resistir à onda que corria contra a ideologia, em parte por causa das próprias políticas de desenvolvimento econômico nacional da ditadura. Um dos aspectos para fazer do Brasil uma potência geopolítica referia-se a melhorar seu sistema de educação superior, ao qual o regime deu alta prioridade. O resultado foi o aumento dramático do número de universidades brasileiras criadas durante os anos 70 . Ao mesmo tempo, tal incremento representou o influxo de um corpo docente jovem, do qual certo número havia obtido graus avançados no exterior.

As experiências de Gilberto Freyre como estudante nos Estados Unidos nos anos 10 e 20 o haviam lançado numa jornada intelectual que acabou levando à formulação da democracia racial. As experiências de outros brasileiros que foram estudar nos Estados Unidos 50 anos depois, em particular daqueles que acabaram estudando raça, levaram a uma direção quase diametralmente oposta. A segregação racial imposta pelo Estado tinha então sido declarada ilegal e os Estados Unidos haviam embarcado num experimento ousado para superar o legado da segregação, por meio de políticas de igual oportunidade e da ação afirmativa. Os movimentos dos direitos civis baseados na raça e no poder negro estavam no auge de sua influência na vida nacional. Dentro da academia, as teorias e os métodos no estudo da raça também transformavam-se. A ascensão da história social e das perspectivas do passado de baixo para cima, e a utilização de novas técnicas quantitativas redefiniam o estudo do escravismo e das relações raciais; mudanças semelhantes ocorriam na sociologia, pelas quais as abordagens quantitativa e macroestrutural do estudo da desigualdade racial deixavam de enfatizar, como anteriormente, os desvios social e cultural dos negros.

O resultado da exposição dos estudantes brasileiros a tais mudanças gerou uma nova onda de pesquisas nos anos 70 e 80 à situação racial brasileira ainda mais críticas do que tinham sido os estudos da Unesco. Os pesquisadores de São Paulo da década de 50 tinham considerado a desigualdade e discriminação racial uma sobrevivência arcaica do período do escravismo, que gradualmente desapareceria à medida que o desenvolvimento e a modernização capitalista abrissem oportunidades crescentes para a mobilidade dos negros em sentido ascendente. Mas os estudiosos cuja formação se deu nos EUA dos anos 70 - notavelmente Carlos Hasenbalg e Nelson do Valle Silva - encontraram poucas evidências de tal abertura, apesar do dramático crescimento econômico ocorrido, tanto nos anos 50 quanto nos anos do milagre: 1968-74. Pelo contrário, demonstraram por cuidadosas análises estatísticas baseadas em censos nacionais e levantamentos de domicílios que os negros e mulatos apresentavam nítida desvantagem com relação aos brancos; e mesmo nos casos em que os afro-brasileiros tinham níveis competitivos de instrução e experiência profissional para o mercado de trabalho, eram preteridos, a favor de brancos com o mesmo preparo, em termos de ganhos e promoção no trabalho. 
Na verdade, quanto maior era o nível educacional dos negros em busca de emprego, mais para trás ficavam em relação aos seus competidores brancos, seja em termos absolutos seja em termos relativos (37).

No Brasil, o crescimento econômico do período pós-guerra havia de fato ampliado as oportunidades para a mobilidade ascensional, mas essas oportunidades eram distribuídas desproporcionalmente em prol dos brancos. Tal fato ocorreu a despeito de aumentos substanciais no número de não-brancos preparados para competir por essas vagas. $\mathrm{O}$ mesmo boom no ensino superior que havia ampliado o número dos cursos universitários também aumentou o número de graduados afro-brasileiros, tanto no segundo grau quanto no ensino superior. Em 1950, somente 48 mil afro-brasileiros (de uma população total de negros e pardos de 16,5 milhões) graduaram-se em escolas de ensino superior e apenas quatro mil no segundo grau. Em 1987, esses números tinham crescido para 2,7 milhões e 485 mil, respectivamente, de uma população total de não-brancos de 59,3 milhões (38). Era um nível de realização educacional consideravelmente menor que o da população branca; ainda assim, produzia um número absoluto significativo de competidores não-brancos para cargos de colarinho branco, como funcionários de escritório, executivos, profissionais liberais e técnicos. Como mostraram os estudos estatísticos e as evidências empíricas, contudo, quando negros e mulatos procuravam obter tais cargos, enfrentavam grandes obstáculos relativos a preconceito e discriminação (39).

Enquanto ponderavam sobre como superar tais obstáculos, os afro-brasileiros instruídos dirigiram sua atenção aos modelos estrangeiros. Entre eles, os movimentos de libertação nacional da África Portuguesa, sob orientação fortemente marxista, que em meados dos anos 70 conquistaram a independência de suas nações com relação à ex-colonizadora do Brasil. Outro modelo referia-se aos movimentos dos direitos civis e do poder negro dos Estados Unidos. Já nas décadas de 20 e 30, durante parte dos períodos mais sombrios da opressão racial nos Estados Unidos, observadores afro-brasileiros haviam notado um paradoxal efeito positivo da segregação sobre o estilo norte-americano: o modo como foram fomentadas as instituições e organizações negras e o sentido de identidade e comunidade racial. "O preconceito é um fato nos Estados Unidos, a odiosa separação das raças", observou O Clarim da Alvorada em 1928, "e foi tal preconceito que tornou o negro norte-americano um homem orgulhoso e altivo ... Ele caminha ereto, intimidando seus terríveis inimigos, seus próprios conterrâneos brancos. E, desta maneira, o negro norte-americano sempre triunfa". Outro jornal, O Progresso, concordava: "É evidente que se os negros que vivem à sombra da Estátua da Liberdade tivessem esperado passivamente pela mão salvadora de alguma entidade oficial, jamais teriam se libertado da servidão legal e econômica que os humilhava e os oprimia. Foi através da ação coletiva ... que as crianças negras do Tio Sam conseguiram se igualar a todas as outras raças nas artes, nas ciências e na economia". Estudando faculdades, igrejas, negócios, organizações cívicas e outras instituições afro-americanas que não tinham correlação no Brasil, O Clarim especulou que talvez "o preconceito gritante e ostensivo seja um estímulo à competência e capacidade do negro" (40). 
Enquanto tais organizações afro-americanas combatiam discriminação e desigualdade, os escritores e intelectuais negros do Brasil perceberam inicialmente os esforços dessas organizações e então, com o passar do tempo, as suas realizações. Durante o final dos anos 40, o jornal Alvorada divulgou artigos sobre E. Philip Randolph, o término da segregação nas forças armadas dos Estados Unidos e outros avanços na campanha contra a segregação, observando que o preconceito e a discriminação pareciam estar em declínio naquele país enquanto, simultaneamente, cresciam no Brasil (4l). Quando a segregação foi então derrotada durante os anos 50 e 60, a imprensa afro-brasileira observou os nítidos avanços na situação racial que lá ocorria e atribuiu o crédito ao movimento de direitos civis dos negros (42). Portanto, por volta da década de 70 , à medida que os não-brancos com mobilidade ascensional começaram a criar as suas próprias organizações e movimentos para combater as barreiras raciais que enfrentavam, muitos voltaram seus olhos para os movimentos dos direitos civis e do poder negro dos Estados Unidos como possíveis modelos a serem seguidos (43).

Tais modelos atraíram com maior força os membros da classe média afrobrasileira. Dentro da classe trabalhadora negra, os Estados Unidos apresentavam outro modelo de ação coletiva, mas de espécie um pouco diferente. Durante os anos 70, jovens negros da classe trabalhadora do Rio, de São Paulo e de outras cidades do Sudeste começaram a promover grandes bailes de fim-de-semana baseados na música soul norte-americana, que freqüentavam usando roupas e penteados seguindo os estilos afros dos Estados Unidos. Este movimento Black Soul (usando as palavras inglesas), com sua importação de estilos culturais e musicais, foi considerado por muitos brasileiros, tanto negros quanto brancos, como uma afronta à identidade nacional brasileira e uma ameaça direta às tradições brasileiras de harmonia e coexistência racial (44). Mas, como observaram vários estudantes do movimento, era esta exatamente a questão: as formas tradicionais de música e dança afro-brasileiras, como o samba, tinham sido tão completamente cooptadas como expressões de brasilidade que os jovens afro-brasileiros, desejosos de expressar uma identidade independente e oposta, tiveram de obter externamente o léxicon cultural nacional para tal. E quando o fizeram, a consciência racial norteamericana (e caribenha - Bob Marley, Jimmy Cliff e outros astros do reggae eram também proeminentemente apresentados nas reuniões do Black Soul) parecia ter sido feita sob medida. Durante esses anos, o "Say it loud: I'm black and I'm proud" [Diga bem alto: sou negro e sou orgulhoso] de James Brown pode ter tido tanto impacto sobre o Brasil quanto teve nos Estados Unidos (45).

Finalmente, a política racial no Brasil foi afetada pelos eventos ocorridos nos Estados Unidos ainda de outra maneira: o financiamento, por parte de fundações norte-americanas, de pesquisas e ativismo sobre a raça iniciado nos anos 70 . Tratava-se de financiamentos pelas Fundações Interamericana e Ford a várias organizações culturais e comunitárias afro-brasileiras. Em parte devido a seu trabalho com essas organizações supostamente subversivas, a Fundação Interamericana foi banida do Brasil pelo governo militar em 1978; desde seu retorno ao país, em 1982, não concedeu novos financiamentos às entidades negras (46). A Fundação Ford, em contraste, recebeu permissão para operar livremente durante todo esse 
período. Seus financiamentos foram crucialmente importantes no apoio a uma variedade de projetos centrados na problemática da raça: conferências e publicações acadêmicas, criação de arquivos sobre a história dos negros, atividades culturais e comunitárias e viagem de estudiosos, intelectuais e ativistas brasileiros aos Estados Unidos para conhecer e consultar seus pares americanos (47). Nos anos 90 a Fundação Ford financiou duas novas e importantes iniciativas: uma campanha nacional para convencer os afro-brasileiros a "não deixar sua cor passar em branco", isto é, não se deixar contar como brancos no censo nacional de 1991 (48); e um programa de bolsas de estudos para enviar, às universidades norteamericanas, estudantes graduados para se especializar em estudos afro-brasileiros e para obtenção de graus avançados.

Portanto, durante o curso da segunda metade do século, inúmeras influências externas se combinaram para minar a hegemonia ideológica da democracia racial no Brasil. Entre elas estavam incluídas as visitas de cidadãos norte-americanos, tanto negros quanto brancos, e os comentários por eles proferidos; os projetos de pesquisa da Unesco; a especialização de jovens brasileiros com curso superior nos Estados Unidos; o exemplo de movimentos negros nos EUA, tanto culturais quanto políticos; e as atividades de fundações norte-americanas no Brasil. Tais influências externas foram particularmente fortes entre dois grupos gerados pelo boom das universidades nos anos 70: afro-brasileiros com segundo grau e curso superior completos, prontos e capazes para competir com os brancos e se introduzir na classe média, frustrados pelas barreiras raciais que os impediam de fazê-lo; e uma nova geração de professores universitários, alguns dos quais realizaram uma pesquisa inovadora sobre a desigualdade racial brasileira como parte de sua crítica mais ampla à desigualdade social no Brasil, em termos mais genéricos. Ativistas negros e acadêmicos brancos, principalmente, viram-se convergindo em sua oposição à democracia racial, convergência essa simbolizada pela bem-sucedida campanha conjunta do Instituto de Pesquisa das Culturas Negras e da Associação Nacional de Pós-Graduação e Pesquisa em Ciências Sociais objetivando recolocar a raça negra no censo de 1980, removida pelo governo militar como categoria de informação do censo de 1970 (49). As desigualdades sociais documentadas nesse censo, por sua vez, forneceram munição adicional para ataques contra aquilo que era cada vez mais denominado de o "mito" da democracia racial.

Durante os anos 80, como resultado desses ataques, a democracia racial perdeu seu domínio inquestionável na vida nacional brasileira. $\mathrm{O}$ fato ficou evidente, em primeiro lugar, na retórica altamente revisionista em torno do centenário da emancipação brasileira de 1988, inclusive nas declarações de altas autoridades do governo e figuras políticas; em segundo, na incorporação de dispositivos antidiscriminatórios grandemente fortalecidos (em comparação com a lei Afonso Arinos) na Constituição de 1988 (50). Ainda assim, relatos de morte da ideologia são muito exagerados. Seus críticos, por mais vocais e eficazes que sejam, continuam minoria na sociedade brasileira. A própria estranheza de suas críticas, que tendem a se basear em modelos e assunções estranhos à experiência histórica do Brasil, torna difícil para a maioria dos brasileiros se identificar com essas críticas e responder a elas. Portanto, a democracia racial e seu sombrio lado inferior de racismo 
aberto e irrefletido permanecem em grande evidência na sociedade brasileira, tanto nas elites quanto nos níveis populares, e continuarão a exercer influência sobre essa sociedade durante algum tempo (51).

\section{O outro lado do diálogo}

Enquanto isso, qual o outro lado deste contraponto americano? Não resta dúvida de que o dilema racial dos Estados Unidos tem tido, ao longo do tempo, impactos significativos sobre a situação racial no Brasil; até que ponto o reverso é verdadeiro?

Durante a primeira metade dos anos 1900, norte-americanos brancos e negros perceberam, e em grande parte aceitaram, as alegações do Brasil de ser uma democracia racial. Depois de visitar o Brasil em 1914, Theodore Roosevelt afirmou: "se me pedissem para dizer um ponto no qual existe uma diferença completa entre nós e os brasileiros, eu diria que é na atitude para com o homem negro... [No Brasil] qualquer Negro ou mulato que se mostre capacitado conquista inquestionavelmente o lugar a que suas capacidades lhe dão o direito" (52). Comentando as observações de Roosevelt, o jornal The Crisis, de W.E.B. DuBois, concordou que "não há a barreira de cor contra o avanço" no Brasil. O Baltimore Afro-American relatou em 1916 que o Brasil "oferece um conhecimento de primeira mão para solucionar a questão racial" e recomendou com veemência aos seus leitores que pensassem em emigrar para lá. "Pareceria que o Brasil seria ao homem de cor instruído de hoje, aquilo que [os] Estados Unidos foram para a Europa em 1850 - uma nova terra e uma terra de promessas. Do ponto de vista do clima e da tradição, o Brasil é um país peculiarmente adaptado para receber o homem de cor deste país e oferecer-lhe uma visão de liberdade e oportunidade muito além de seus sonhos mais desvairados" (53).

Outros jornais dedicados a temas da raça negra, entre eles o Atlanta Independent, o Negro World e o Chicago Defender, publicaram artigos semelhantes durante os anos 1910 e 1920, encorajando a migração negra ao Brasil (54). Os norte-americanos africanos que perseguiram tal idéia, contudo, logo descobriram o contínuo compromisso das autoridades consulares brasileiras para com a tese do branqueamento tendo sido negado a muitos deles o visto para entrar no país, mesmo como turistas (55). Por volta dos anos 40, a atitude dessa mesma imprensa dos EUA com relação ao Brasil estava começando a mudar. DuBois estava na vanguarda, escrevendo em 1941 que a mistura racial celebrada por Freyre e outros proponentes da democracia racial "não imagina nenhuma diminuição de poder e prestígio entre os brancos ... mas, antes, uma inclusão dentro do assim chamado grupo branco de uma considerável infiltração de sangue negro, ao mesmo tempo em que mantém a barreira social, a exploração econômica e a privação dos direitos políticos do sangue negro como tal... Portanto, o amálgama racial na América Latina nem sempre e nem habitualmente carrega consigo a ascensão social e o esforço planejado para levar o mulato e os mestiços à liberdade numa sociedade civil democrática". O Baltimore Afro-American, que em 1916 recomendara com veemência a migração negra ao Brasil, publicou uma série de artigos em 1940 sobre "a 
linha da cor na maior República da América do Sul". George Schuyler, editor do Pittsburgh Courier, divulgou uma reportagem igualmente negativa em Brazilian Color Bias após sua visita ao Brasil em 1948 e continuou, durante os anos 50, a publicar artigos ocasionais do Quilombo mensal afro-brasileiro, editado pelo ativista Abdias do Nascimento (56).

A opinião acadêmica nos Estados Unidos levou mais tempo para se inverter. Durante os anos 40, os estudiosos norte-americanos continuavam a nutrir forte admiração pela democracia racial, particularmente quando comparavam as relações raciais brasileiras com a segregação e discriminação documentadas no estudo de Gunnar Myrdal, An American dilemma: the negro and modern democracy, de 1944 (57), considerado um marco. A pesquisa realizada por Donald Pierson sobre as relações raciais na Bahia e o importante estudo comparativo de Frank Tannenbaum, Slave and citizen: the negro in the Americas (1946), seguiam à risca as linhas traçadas por Gilberto Freyre. O livro de Tannenbaum de fato abria com um tributo ao "frescor e lucidez" de "tudo o que Gilberto Freyre escreve", e então prosseguia ampliando os argumentos de Freyre, relacionando o Brasil à América Latina como um todo (58).

Foi a fé dos estudiosos norte-americanos e europeus nas virtudes da democracia racial que levou aos projetos de pesquisa da Unesco no início dos anos 50. Os achados negativos desses projetos inspiraram uma segunda onda de trabalhos comparativos nos anos 70. Entre eles, um impressiona de fato pelo grau em que os comparativistas norte-americanos seguiram a orientação definida pelos principais pesquisadores brasileiros: embora Tannenbaum baseasse parte considerável de sua análise em Freyre, uma segunda geração de comparativistas no final das décadas de anos 60 e 70 também se apoiou pesadamente nos revisionistas da Unesco, particularmente Florestan Fernandes. Como resultado, formularam comparações bem mais ambivalentes entre os Estados Unidos e o Brasil (59). Mesmo as visões mais críticas dos estudiosos brasileiros que escreveram nos anos 70 e 80 , somente agora começam a produzir uma terceira onda de estudos comparativos nos Estados Unidos que inverte, em sua essência, a visão original de Freyre e Tannenbaum. O recente exame feito por Thomas Skidmore das categorias e taxonomia raciais nos dois países estuda as afirmativas há muito existentes sobre as diferenças fundamentais entre o sistema dicotômico negro-branco e o continuum de cor pretopardo-branco mais flexível do Brasil, concluindo que essas asserções "não resistirão à análise dos dados quantitativos" gerados por pesquisadores brasileiros. Como demonstraram Silva, Hasenbalg, entre outros, as populações de negros e mulatos do Brasil não diferem muito entre si na maioria dos indicadores sociais e econômicos - expectativa de vida, renda, educação -, embora ambos os grupos sejam nitidamente diferenciados dos brancos. As relações raciais brasileiras parecem, portanto, bem mais bipolares do que tradicionalmente se pensava; reciprocamente, a dicotomia negro/branco nos Estados Unidos está se fragmentando face tanto à maciça imigração da América Latina e da Ásia quanto às novas identidades multirraciais. Os grupos raciais e étnicos de crescimento mais rápido nos Estados Unidos não são, para tomar emprestado o título do estudo comparativo de Degler, "nem negros nem brancos" (60). 
Outra inversão nos termos tradicionais de comparação entre os Estados Unidos e o Brasil é um recente estudo dos indicadores estatísticos, o qual constata que durante a primeira metade dos anos 1900, o Brasil foi, em termos raciais, o mais igualitário dos dois países. Desde a década de 50 , contudo, tal relação se inverteu, tornando os Estados Unidos, em termos estatísticos, "a sociedade racialmente mais igual - ou, numa melhor colocação, a menos desigual - entre as duas". Depois de cair durante os anos 60 e 70, os índices de desigualdade racial aumentaram nos Estados Unidos durante a década de 80. Não obstante, continuaram mais baixos que os do Brasil, levando o autor a concluir que os Estados Unidos oferecem "evidências mais convincentes de democracia racial” que o Brasil (61).

Nesse trabalho recente, portanto, os termos de comparação EUA-Brasil foram radicalmente alterados. O Brasil, além de não ser mais considerado uma democracia racial, seu sistema de relações raciais já não é tido como superior ao dos Estados Unidos praticamente em maneira alguma (62). Seriam tais aspectos resultantes de um revisionismo excessivo? O tempo e o próximo giro da roda acadêmica o dirão. Nesse meio tempo, podemos concluir este ensaio observando como a roda girou até agora e como tem sido impulsionada para frente pelo intercâmbio intelectual trans-hemisférico.

\section{Conclusão}

Durante o transcorrer do século, uma seqüência de estudiosos e intelectuais brasileiros - Gilberto Freyre nos anos 30 e 40, Florestan Fernandes e os revisionistas da Unesco nas décadas de 50 e 60, Carlos Hasenbalg e Nelson do Valle Silva nos anos 70 e 80 - produziram importantes reconceituações das relações raciais brasileiras (63). Foram estimulados a fazê-lo, em grande parte, devido ao seu contato, seja direto seja indireto com os Estados Unidos: Freyre, Hasenbalg e Silva através de seus estudos nos EUA; e Fernandes por meio de seus contatos intelectuais, primeiro com a escola de sociologia de Chicago e depois com a Divisão de Ciências Sociais da Unesco. Tais reconceituações, por sua vez, moldaram as análises realizadas por sucessivas gerações de comparativistas norte-americanos: Tannenbaum, Harris, van den Berghe, Degler, Toplin, Skidmore, entre outros.

Segundo tal padrão, é de se supor que o próximo giro da roda exigirá reconceituação adicional que, no Brasil, seria resposta, em parte, novamente aos estímulos e provocação oriundos dos Estados Unidos. Também poder-se-ia pressupor que tal reconceituação é iminente e deverá ocorrer nesta década. É impressionante notar que, até o presente, a precisão dessa periodicidade seja comparável à de um relógio. Pensadores brasileiros formulam uma nova e revisada visão das relações raciais em seu país e, de dez a quinze anos depois, estudiosos norteamericanos respondem com novas sínteses comparativas. Assim, Freyre dos anos 30, seguido por Tannenbaum nos anos 40; pesquisadores da Unesco nos anos 50, seguidos por, entre outros, van den Berghe, Degler, Skidmore no final dos anos 60 e início dos 70; posteriormente Hasenbalg e Silva no fim dos anos 70, seguidos por novos esforços comparativos no início da década de 90. A mudança é igualmente regular no lado brasileiro, no qual cada grande reformulação ocorre de 
cinco a 10 anos após os esforços comparativos norte-americanos: depois de Tannenbaum, os pesquisadores da Unesco; e depois de Degler et al., Hasenbalg e Silva.

Caso tal padrão se mantenha, os esforços comparativos dos anos 90 pressagiariam uma nova formulação brasileira, logo antes ou pouco depois do ano 2000. Embora vacilemos em prognosticar de maneira tão mecânica, existe de fato uma boa razão para antecipar tal desenvolvimento. Atualmente, o Brasil está vivenciando profundas crises econômica, social e política que prejudicam o país desde a restauração do governo civil em 1985. Inflação, pobreza, fome e morte por inanição, corrupção política, crime nas ruas - cada um desses problemas, há muito endêmicos, intensificou-se dramaticamente nos últimos dez anos, empurrando o Brasil, não é exagero afirmar, para a beira de uma crise moral da identidade nacional (64). Um momento de convulsão nacional desse tipo, nos anos 30, lançou Gilberto Freyre na sua recriação de passado, presente e futuro brasileiros. Pode-se supor que a atual crise esteja incitando igual busca entre os intelectuais brasileiros e recriações análogas da imagem Brasil como sociedade e nação. E já que a questão da raça continua tão central para a identidade nacional brasileira nos anos 90 como o era nos anos 30, essas imagens e visões provavelmente incluirão mais uma mudança de paradigma nas conceituações brasileiras de sua sociedade multirracial. Assim como o monumental trabalho de Freyre começou a ser gerado durante seus anos como estudante no Texas e em Nova Iorque, também as sementes de tal mudança poderão estar germinando neste exato momento nas mentes daqueles estudantes de história, sociedade e cultura afro-brasileira atualmente matriculados em universidades norte-americanas. Se assim for, seu trabalho constituirá um novo capítulo de um contínuo contraponto americano que já dura um século.

Notas

1 A partir de 1987 (os resultados do censo de 1991 ainda não foram inteiramente tabulados), a população de negros e pardos do Brasil era de 59,3 milhões, de uma população total de 138,5 milhões. Rio de Janeiro, Instituto Brasileiro de Geografia e Estatística (IBGE), Pesquisa nacional por amostra de domicilios - 1987. Cor da população, v. 1, 1990, p. 2-3.

2 Citações de Cem anos depois, Folha de S. Paulo, 13 maio 1988, p. 2; Cem anos, sem quase nada, Istoé, 20 abr. 1988, p. 30-33; Cem anos de solidão, Caderno B, Jornal do Brasil, 8 maio 1988. Sobre as mudanças ao longo do tempo nas descrições das relações raciais brasileiras, veja Pierre-Michel Fontaine, Research in the political economy of Afro-Latin America, Latin American Research Review, v. 12, n. 1, p. 111-141, 1980; Thomas E. Skidmore, Race and class in Brazil: historical perspectives. In PierreMichel Fontaine (ed.), Race, class and power in Brazil. Los Angeles, 1985, p. 11-24. Para um trabalho recente sobre relações raciais brasileiras, veja Carlos Hasenbalg, Discriminação e desigualdades raciais no Brasil. Rio de Janeiro, 1979; Fontaine, Race, class and power; Lúcia Elena Garcia de Oliveira et al., O lugar do negro na força de trabalbo. Rio de Janeiro, 1985; George Reid Andrews, Blacks and whites in São Paulo, Brazil, 1888-1988, Madison, 1991; Peggy Lovell (ed.), Desigualdade racial no Brasil contemporâneo. Belo Horizonte, 1991; Michael George Hanchard, Orpheus 
and power: the movimento negro of Rio de Janeiro and São Paulo, Brazil, 1945-1988. Princeton, 1994.

3 Andrews, op. cit., p. 4, 16, 129-134, 224-226; George Reid Andrews, Black political mobilization in Brazil, 1975-1990. In: George Reid Andrews \& Herrick Chapman (eds.) The social construction of democracy, 1870-1990. Londres, 1995.

4 Sobre as reverberações dos diálogos conceituais transnacionais, veja Steve J. Stern, Africa, Latin America, and the splintering of historical knowledge: from fragmentation to reverberation. In: Frederick Cooper et al., Confronting historical paradigms: peasants, labor, and the capitalist world system in Africa and Latin America. Madison, 1993 , p. 3-20. Sobre a latino-americanização das relações raciais nos Estados Unidos, veja Thomas E. Skidmore, Bi-racial USA vs. multi-racial Brazil: is the contrast still valid?, Journal of Latin American Studies, v. 25, n. 2, p. 373-86, 1993 discutido abaixo; Peter Wade, Blackness and race mixture: the dynamics of racial identity in Colombia. Baltimore, 1993, p. 338-339, 343-346.

5 Thomas E. Skidmore, Black into white: race and nationality in Brazilian thought. Nova Iorque, 1974, p. 27-69.

6 Thomas W. Merrick \& Douglas H. Graham, Population and economic development in Brazil, 1800 to the present. Baltmore, 1979, p. 92. Estes imigrantes, e sua descendência nascida brasileira, representaram uma adição substancial à população do Brasil, que era de apenas 14 milhões em 1980, e de 31 milhões em 1920.

7 Evolução da raça, In: Ministério da Agricultura, Indústria, e Comércio, Diretoria Geral de Estatística, Recenseamento do Brasil, realizado em I de setembro de 1920. Rio de Janeiro, 1922, v. 1, p. 334, 340; ênfase no original. Este ensaio voltou a ser publicado separadamente como uma monografia, Evolução do povo brasileiro. Seu autor, Francisco José Oliveira Viana, foi um importante pensador político conservador e era, assim como Nina Rodrigues, pessoa de raça mista. Veja Jeffrey D. Needell, History, race, and the State in the thought of Oliveira Viana, Hispanic American Historical Review, v. 75, n. 1, 1995.

8 Sobre as tensões causadas pela europeização, veja Boris Fausto, Trabalho urbano e conflito social, 1890-1920. São Paulo, 1977; Sheldon Maram, Anarquistas, imigrantes, e o movimento operário brasileiro, 1890-1920. Rio de Janeiro, 1979; Sidney Chalhoub, Trabalho, lar e botequim: vida cotidiana e controle social da classe trabalhadora no Rio de Janeiro da Belle Epoque. São Paulo, 1986; June Hahner, Poverty and politics: the urban poor in Brazil, 1870-1920. Albuquerque, 1986.

9 Hahner, op. cit., p. 50-55; Steven Topik, Middle-class Brazilian nationalism, 18891930, Social Science Quarterly, v. 59, n. 1, p. 93-103, 1978.

10 Joseph L. Love, São Paulo in the Brazilian Federation, 1889-1937. Stanford, 1980, p. 12; Robert M. Levine, The Vargas regime: the critical years, 1934-1938. Nova Iorque, 1970, p. 39; Decreto 20.921, Diário Oficial dos Estados Unidos do Brasil, 25 ago. 1931, p. $13,552-558$.

11 Veja a história do Brasil em três partes de Freyre, Casa grande e senzala (1933), Sobrados e mucambos (1936), e Ordem e progresso (1959), que foram traduzidos para o inglês como The masters and the slaves: a study in Brazilian civilization. Nova Iorque, 1946; The mansions and the shanties: the making of modern Brazil. Nova Iorque, 1963; e Order and progress: Brazil from monarchy to republic. Nova Iorque, 1970. 
Veja também suas sínteses em língua inglesa, Brazil: an interpretation. Nova Iorque, 1945 e New world in the tropics. Nova Iorque, 1959.

12 Sobre as experiências de Freyre nos Estados Unidos e os impactos que tiveram sobre a sua obra, veja Jeffrey D. Needell, Identity, race, gender, and modernity in the origins of Gilberto Freyre's Oeuvre, American Historical Review, v. 100, n. 1, 1995.

13 Freyre, Masters and the slaves, p. xii.

14 Freyre, Mansions and shanties, p 416, 431.

15 Escrevendo em 1945, Freyre contrastou diretamente a democracia racial brasileira com o racismo nazista, argumentando que "somos incapazes de conceber uma sociedade com tendências mais opostas àquelas do Weltanschauung germânico". Freyre, Masters and the slaves, p. xiv.

16 Lívio de Castro, Questões e problemas: ódio entre as raças, A Província de São Paulo, 6 fev. 1889.

17 Evaristo de Moraes, Expansão de um preconceito, Getulino, 10 fev. 1924, p. 1; Evaristo de Moraes, Brancos e negros nos Estados Unidos e no Brasil. Rio de Janeiro, 1922, p. 55 .

18 A inquisição moderna, Clarim da Alvorada. 14 nov. 1926, p. 2-3. Veja também O Ku Klux Klan, Getulino, 23 nov. 1924, p.1; “A questão de raça, Auriverde, 29 abr. 1928, p. 3; Lynchamento, Progresso, 26 set. 1929, p. 6; Ku Klux Klan, Alvorada, 13 maio 1946, p. 5; Civilização ou barbárie, Alvorada, ago. 1934, p. 4; A voz dos Estados Unidos, O Novo Horizonte, maio 1947, p. 3-4; Repúdio de homens de côr ao ódio racista de Alabama e nos EUA negro é tragédia, Correio d'Ébano, 16 jun. 1963, p. 3 , 5. Sobre a imprensa afro-brasileira, veja Roger Bastide, A imprensa negra no estado de São Paulo, in Bastide, Estudos afro-brasileiros. São Paulo, 1983; Miriam Nicolau Ferrara, A imprensa negra paulista (1915-1963). São Paulo, 1986; Imprensa negra. São Paulo, 1984.

19 Cartas d'um negro, Getulino, 21 out. 1923, p. 3.

20 Quem somos, O Clarim da Alvorada, 14 nov. 1926, p. 3 ; 13 de maio, O Clarim da Alvorada, 13 maio 1930, p. 1. Para julgamentos igualmente negativos da democracia racial, veja Para os nossos leitores, O Alfinete, 22 set. 1918, p. 1; Preto e branco, Kosmos, 18 abr. 1923, p. 1; Os pretos em São Paulo, Kosmos, 19 out. 1924, p. 1; O grande problema nacional, Evolução, 13 maio 1933, p. 9 e 13.

21 Andrews, Blacks and whites, p. 137-138.

22 O próprio Freyre enfatizou que foram os mulatos, e não os negros, que tinham colhido os benefícios do igualitarismo racial do Brasil. Veja The rise of the college graduate and the mulatto. In: Mansions and shanties, p. 354-399.

23 Para uma defesa da superioridade do mulato, veja Evaristo de Moraes, A ascenção dos mulatos, Getulino, 13 out. 1923, p. 3. Para ataques de tais pretensões, veja Parece incrível, O Alfinete, 22 set. 1918, p. 3; Vagando, A Liberdade, 14 dez. 1919, p. 1-2; Carta aberta, Getulino, 2 nov. 1924, p. 1; Parabéns, Viriato!, Progresso, 28 abr. 1929, p. 3.

24 Florestan Fernandes, A integração do negro na sociedade de classes [relatório], São Paulo, 1978 [1964], v. 2, p. 23, n. 11; José Correia Leite e Cuti, ... E disse o velho militante José Correia Leite. São Paulo, 1992, p. 59-72. 
25 José Correia Leite, Preconceito, casa grande, e senzala, Alvorada, mar. 1947, p. 1. Esta foi uma referência irônica ao primeiro livro de Freyre, Casa grande e senzala.

26 Veja, por exemplo, Eugene Gordon, An essay on race amalgamation. Rio de Janeiro, 1951, publicado pelo Ministério das Relações Exteriores, com um prefácio de Freyre.

27 Charles Wagley (ed.), Race and class in rural Brazil. Paris, 1952, particularmente o último capítulo, From caste to class in Northern Brazil, p. 142-156. Tais achados tenderam a ecoar o importante estudo anterior do sociólogo Donald Pierson, Negroes in Brazil: a study of race contact in Bahia. Chicago, 1942. Veja também Thales de Azevedo, Les élites de couleur dans une ville brésilienne. Paris, 1953.

28 Roger Bastide \& Florestan Fernandes, Brancos e negros em São Paulo [relatório], São Paulo, 1971 [1953]; Luis de Aguiar Costa Pinta, O negro no Rio de Janeiro. São Paulo, 1953.

29 David J. Hellwig, African-American reflections on Brazil's racial paradise. Filadélfia, 1992, p. 61, 64, 92-93, 145-146; Preto e branco, Kosmo, 18 abr. 1923, p. 1; Corajosa afirmação, Alvorada. fev. 1947, p. 1.

30 Carl Degler, Neither black nor white: slavery and race relations in Brazil and the United States. Nova Iorque, 1971, p. 138; Skidmore, Black into white, p. 212.

31 Peter R. Eccles, Culpados até prova em contrário: os negros, a lei e os direitos humanos no Brasil, Estudos Afro-Asiáticos, n. 20, p. 140-142, 1991; Porteiro racista só pagará multa, Folba de S. Paulo, 23 set. 1975. No estado mais populoso do Brasil, São Paulo, somente 23 queixas foram apresentadas sob a lei durante aquele período (1954-1988), e em nenhuma delas os tribunais procuraram pelo queixoso. Racismo em São Paulo motiva 64 processos em 2 anos, Folba de S. Paulo, 27 jan. 1991.

32 Veja, por exemplo, Edgard T. Santana, Relações entre pretos e brancos em São Paulo, 1951; Alberto Guerreiro Ramos, Introdução crítica à sociologia brasileira. Rio de Janeiro, 1957. Sobre as reações afro-brasileiras locais aos projetos, veja Edison Carneiro, Ladinos e crioulos, Rio de Janeiro, 1964, p. 102-118; Abdias do Nascimento (ed.), O negro revoltado, $2^{\text {a }}$ ed. Rio de Janeiro, 1982, p. 235-242.

33 Thales de Azevedo, Cultura e situação racial no Brasil. Rio de Janeiro, 1966; Democracia racial. Petrópolis, 1975. Florestan Fernandes, op. cit. (traduzido para o inglês como The Negro in Brazilian society. Nova Iorque, 1969; O negro no mundo dos brancos. São Paulo, 1972; O significado do protesto negro. São Paulo, 1989. Para conhecer alguns dos trabalhos de seus alunos, veja Fernando Henrique Cardoso, Capitalismo e escravidão no Brasil meridional: o negro na sociedade escravocrata no Rio Grande do Sul. São Paulo, 1962; Octávio Ianni, As metamorfoses do escravo: apogeu e crise da escravatura no Brasil meridional. São Paulo, 1962; Raças e classes sociais no Brasil. São Paulo, 1970; Escravidão e racismo. São Paulo, 1978; Fernando Henrique Cardoso \& Octávio Ianni, Côr e mobilidade social em Florianópolis. São Paulo, 1960.

34 Veja, por exemplo, Oracy Nogueira, Atitude desfavorável de alguns anunciantes de São Paulo em relação aos empregados de cor, Sociologia, v. 4, n. 4 p. 328-358, 1942.

35 Azevedo, Democracia racial, v. 53, n. 27.

36 Gilberto Freyre, A propósito de preconceito de raça no Brasil, O Estado de S. Paulo, 25 jun. 1969.

37 Os trabalhos primordiais desta área foram as dissertações para a obtenção de Ph.D. de 
Hasenbalg e de Silva: Carlos A. Hasenbalg, Race relations in post-abolition Brazil: the smooth preservation of racial inequalities. University of California-Berkeley, 1978, posteriormente publicado no Brazil como Discriminação e desigualdades raciais no Brasil. Rio de Janeiro, 1979; Nelson do Valle Silva, Black-white income differentials: Brazil, 1960. University of Michigan, 1978. Para trabalhos posteriores desses autores, veja seus ensaios em Fontaine, Race, class and power, e os livros dos quais foram coautores, Estrutura social, mobilidade e raça. Rio de Janeiro, 1988 e Relações raciais no Brasil. Rio de Janeiro, 1992. Para outros trabalhos importantes desse tipo, veja Oliveira et al., op. cit., Lovell, op. cit., e o trabalho publicado na revista editada por Hasenbalg, Estudos Afro-Asiáticos. Veja também o trabalho do sociólogo afro-brasileiro Clóvis Mouse, O negro: de bom escravo a man cidadão? Rio de Janeiro, 1977; Sociologia do negro brasileiro. São Paulo, 1988; Dialética radical do Brasil negro. São Paulo, 1994.

38 IBGE, Recenseamento geral de 1950. Censo demográfico: Estados Unidos do Brasil. Rio de Janeiro, 1956, p. 24; IBGE, Pesquisa nacional-1987, v. 1, p. 8 e 10.

39 Para uma evidência pessoal expressiva, veja Haroldo Costa, Fala, crioulo. Rio de Janeiro, 1982.

$40 \mathrm{Na}$ terra do preconceito, O Clarim da Alvorada, 4 mar. 1928, p. 3; Povo que não se abate, Progresso, 15 nov. 1931, p. 3; Eduquemos nosso povo, O Clarim da Alvorada, 28 set. 1931, p. 4. Veja também Aos nossos leitores, O Alfinete, 3 set. 1918, p. 1.

41 Corajosa afirmação, Alvorada, fev. 1947, p. 1; e a coluna regular Mundo Negro.

42 Veja, por exemplo, A posição do negro nos Estados Unidos, Hifen, fev. 1960, p. 6; O Harlen [sic] desconhecido, Hifen, jul. 1960, p. 4; Harlem: inferno ou paraiso?, Jornegro, set. 1978, p. 4-5.

43 Sobre o movimento dos anos 70 e 80, veja Andrews, Blacks and whites, p. 191-207; Hanchard, op. cit., p. 109-141.

44 Não é de surpreender que Gilberto Freyre estivesse à frente dos protestadores. Veja seu artigo Atenção brasileiros, publicado na página oposta à do editorial do Diário de Pernambuco, 15 maio 1977, citado em Hanchard, op. cit., p. 115.

45 Sobre o Black Soul e as reações a ele, veja Hanchard, op. cit., p. 111-119; Hermano Viana, O mundo funk carioca. Rio de Janeiro, 1988; Lauro Cavalcanti, Black-breque. Estudo de um grupo soul em relação a adeptos do samba, Comunicações do ISER, v. 7, n. 28, p. 21-32, 1988.

46 Skidmore, Race and class, p.16; entrevista com John Garrison, Inter-American Foundation, 15 dez. 1994.

47 Um artigo interessante sobre as atividades da Fundação Ford nesta área ainda não foi escrito. Este parágrafo baseia-se na minha própria participação em alguns desses projetos e em conversas, ao longo dos anos, com funcionários e consultores de programas da Fundação.

48 Regina Domingues, The color of a majority without citizenship, Conexões, v. 4, n. 2, p. 6-7, nov. 1992. Os recenseadores brasileiros são obrigados a aceitar as próprias declarações do indivíduo sobre a sua identidade racial, e freqüentemente se conjectura que muitos afro-brasileiros se rotulem de brancos. Veja Charles Wood, Categorias censitárias e classificações subjetivas de raça no Brasil. In: Lovell, op. cit., p. 93-111. 
49 Censo-80 vai pesquisar cor, decide o IBGE, Folha de S. Paulo, 9 nov. 1979, p. 6.

50 Nas cerimônias na capital nacional que marcaram o centenário, o ministro da Cultura, Celso Furtado, cujo ministério foi o responsável pela coordenação das festividades nacionais, declarou que "a idéia de que exista democracia racial no Brasil é falsa uma vez que a grande maioria da população negra vive marginalizada e na pobreza". Vem aí cem anos de ebulição, A Gazeta, 13 maio 1988. O candidato do Partido dos Trabalhadores à presidência da república Luis Inácio "Lula" da Silva, que recebeu $47 \%$ dos votos nacionais nas eleições de 1989 , denunciou a democracia racial como um apartheid de facto, representando "a supremacia de uma elite branca dominante que enxerga uma correlação direta entre cor da pele e as possibilidades de acesso aos direitos e ao poder". Luis Inácio "Lula" da Silva, A mistificação da democracia racial, Folha de S. Paulo, 16 fev. 1988, p. 3. Sobre os eventos de 1988, veja Andrews, Blacks and whites, p. 211-233; Hanchard, op. cit., p. 142-154; Yvonne Maggie, Catálogo: centenário da abolição, Rio de Janeiro, 1989.

51 Veja, por exemplo, a discussão da antropóloga Nancy Scheper-Huges, baseada em seu trabalho de campo numa cidade do nordeste brasileiro, de como "a ideologia da democracia racial ... [está passando] sem discussão e sem contestação, para a próxima geração", acompanhada de "sentimentos racistas que eram antes desaprovados, pelo menos publicamente". Nancy Scheper-Hughes, Death without weeping: the violence of everyday life in Brazil. Berkeley, 1992, p. 90 e 92.

52 Theodore Roosevelt, Brazil and the negro, Outlook, 21 fev. 1914, p. 410-411.

53 Hellwig, op. cit., p. 32, 35-36.

54 Ibid., p. 37-81; David J. Hellwig, A new frontier in a racial paradise: Robert S. Abbott's Brazilian dream, Luso-Brazilian Review, v. 25, n. 1, p. 59-68, 1988.

55 Teresa Meade \& Gregory Alonso Pirio, In search of the Afro-American Eldorado: attempts by North American blacks to enter Brazil in the 1920s, Luso-Brazilian Review, v. 25, n. 1, p. 85-110, 1988; Jeff H. Lesser, Are African-Americans African or American? Brazilian immigration policy in the 1920s, Review of Latin American Studies, v. 4, n. 1-2, p. 115-37, 1991.

56 Hellwig, African-American Reflections, p. 91-108, 119, 145-158.

$57 \mathrm{O}$ estudo de Myrdal (sociólogo suéco) exemplifica vários fenômenos observados neste ensaio: as influências transnacionais sobre a conceituação de problemas raciais; $\mathrm{o}$ papel das fundações norte-americanas na promoção de tal transnacionalização (seu projeto foi comissionado pela Carnegie Corporation). Veja David W. Southern, Gunnar Myrdal and black-white relations: the use and abuse of an American dilemma, 1944-1969. Baton Rouge, 1987.

58 Frank Tannenbaum, Slave and citizen: the negro in the Americas. Nova Iorque, 1946, p. 3. Veja também Pierson, op. cit., e as avaliações geralmente positivas da situação racial brasileira dos estudiosos afro-americanos Franklin Frazier \& Lorenzo Turner. Hellwig, African-American reflections, p. 121-136, 159-165.

59 Esta ambivalência foi habilmente capturada no livro Neither black nor white, de Carl Degler; veja também seus comentários, considerando "as nuanças das relações raciais no Brasil tão complexas, e não obstante tão simples, tão diferentes, e não obstante tão semelhantes àquelas nos Estados Unidos ...”. Veja também Pierre van den Berghe, Race and racism: a comparative perspective. Nova Iorque, 1967; Robert Brent Toplin, 
Freedom and prejudice: the legacy of slavery in the United States and Brazil. Westport, Connecticut, 1981, ambos fortemente influenciados por Fernandes. Marvin Harris, Patterns of race in the Americas. Nova Iorque, 1964, aceita as descrições de Freyre e de Tannenbaum sobre a situação brasileira - as identidades raciais flexíveis, a ausência de barreiras de cor, a relativa integração dos não-brancos à vida nacional -, mas propõe explicações materialistas, e não culturais, para essa situação. Veja também Thomas E. Skidmore, Toward a comparative analysis of race relations since abolition in Brazil and the United States, Journal of Latin American Studies, v. 4, n. 1, p. 1-28, 1972.

60 Skidmore, Bi-racial USA vs. muti-racial Brazil; Lawerence Wright, One drop of blood, The New Yorker, 25 jul. 1994, p. 46-55.

61 George Reid Andrews, Racial inequality in Brazil and the United States: a statistical analysis, Journal of Social History, v. 26, n. 2, p. 229-263, 1992. Para obter uma visão comparativa menos apaixonada dos Estados Unidos, também com a utilização de dados estatísticos, veja I.K. Sundiata, Late twentieth-century patterns of race relations in Brasil and the United States, Phylon, v. 48, n. 1, p. 62-76, 1987.

62 Esta inversão pode ser observada na ironia não-intencional manifesta no artigo de um jornal brasileiro sobre o racismo nos Estados Unidos, no qual a autora revela sua surpresa ao descobrir ser, naquele país, tão ruim como no Brasil. O racismo nos EUA, igualzinho ao Brasil, O São Paulo, 30 mar. 1984, p. 6.

63 Duas dessas personalidades - Roger Bastide (o colaborador de Fernandes) e Carlos Hasenbalg - não eram de fato brasileiros. Bastide era francês e Hasenbalg argentino. Entretanto, os dois viveram no Brasil durante períodos prolongados - Bastide, durante 16 anos, Hasenbalg por mais de 20 - e se integraram completamente à comunidade intelectual brasileira.

64 Sobre vários aspectos dessa crise, veja Scheper-Hughes, op. cit.; Gilberto Dimenstein, Brazil: war on children. Londres, 1991; Peter Flynn, Collor, corruption, and crisis: time for reflection, Journal of Latin American Studies, v. 25, n. 2, p. 351-71, 1993.

George Reid Andrews é professor do Departamento de História da Universidade de Pittsburg (EUA).

Tradução de Vera de Paula Assis. O original em inglês - Brazilian racial democracy, 1900-1990: an american counterpoint - encontra-se à disposição do leitor no IEA-USP para eventual consulta. 